\title{
SRETCII OF AN ENDEMIC TYPHOID FEVER WHICII OCCURRED IN DRYDEN, TOMPKINS CO., N. Y.
}

[Communicuted for the Boston Medicul and Surgical Journal.]

Epidemic and endemic fevers have been the great scourge of this country. Their malignancy has consigned youth and the middle aged particularly to a premature grave. What has been said of consumption applies also to fever, that it preys not on the thorns and brambles of this wilderness, but on the rose and passion flower of human excellence and gentleness. The endemic, now to be described, broke out about the middle of July, 1842. There were about eighty cases within and near the village from that time until the first of November, when it began to abate. Cases of it, however, continued to recur for the two succeeding years. Twelve, among those first attacked, terminated fatally. This disease probably arose from marsh miasmata, as the village is surrounded by low, wet land, which was covered with decaying trees, stumps, and other vegetable matter. There was also a mill dan erected about a mile fion it the year previous, and much land partially overflowed. The stream which passes through the village is very slow, and was obstructed in many places by flood wood. Internittents formerly prevailed here, and we have the opinion of the illustrious Armstrong that marsh miasmata is the primary source of typluss. It is probable that the fever was not propagated by contagion. Those who nursed the sick in the village were : generally attacked, but on being conveyed to their homes they did not infect others. Members of the same family were too often attacked siinulaneously for us to suppose that it was communicated from one to another.

Symptoins. - I will pass over those common to continued fever, and confine myself mostly to those peculiarities which might, perhaps, distinguish this endemic from an equal number of other case's of continued fever as it commonly appears. 'The tongue was either coated and preternaturally red at the edges, or clean with this appearance over its whole surface. After pressure the color quickly returned in it. There was an uneasy sensation of the bowels, producing an impression on the mind of the patient that there was something in them which should be removed. This sensation was, however, increased by active cathartics, as was tyınanitis, which often occurred. Diarrhoa was common, and the howels, in all cases, were very easily moved. Profuse hemorhage from the bowels was fiequent. In inost cases thore was slight cough. In some instances there were symptoms of local disease of the brain or some other vital organ. The morning remissions and evening exacerbations were strongly makked. Pulse usually 120. In the advaneed stages dedirium, subsultus tendinum and involuntary discharges from the bowels, occasionally took place.

Post-mortcm Appearances. - These showed marks of inflammation of the mucous membrane of the small intestines, and ulcerations from the size of a grain of wheat to that of a sixpence. These in some instances had produced perforations through other coats of the bowels. In 
one case the pericardium was lined with coagulable lymph, and the surface of the heart was much denuded.

Treatment.-It was found that the treatment with emetics and repeated drastic catbartics was very unsuccessful. Most of the futal cases occurred under this practice. 'The physician who would attack this form of fever indiscriminately with such means, might display heroic practice; but, like other heroes, he would destroy life. It was rare that a patient could withstand both inflammation of the mucous membrane, and the exterminating attack made on it. At the commencement, however, if the stomach was oppressed with undigested food, an enctic of ipecalc. was beneficial ; so, also, if there was a loaded state of the bowels, a blue pill or teaspoonful of castor oil was indicated. But, as a greneral rule, it was found best to keep the bowels open with laxative conemas only. I shall confine myself to an account of the remedies used in the successful cases. Bloodletting in the stage of excitement was olien a sale measure, from its tendency to prevent inflammation. When this took place early, vencsection was of course indispensable. A very small pertion of bluod from the arm made an impression. Cups on the abdomen were used. During the forming stage, the wam bath appe:ared to do good. 'This retisedy was useful during protracted convalescence attended with a dry skin and wakefulness. Whon the skin was hot and dry, in the stage of excitement, spongine with cool water, and. cool injections into the bowels. were useful. Drinks were lemonade and ice water. During the artive stage, spirits of Mindereri. difuted with water, was used as a debrifuge. Morphine in small doses, to allay irritation and check diarrhoea. Stimulants in the latter stages, under symptoms of prostration. Simapisms were applied to alsdomen.

1. S. Briges, M.D.

Dryden, N. Y., July 14th, 1845.

\section{LIQUID COMPOUND OF IODINE AND MORPIIA.}

To the Editor of the Boston Medical and Surgical Journal.

Drar Sir,-After I first became acquainted with the powers of iodine, complications of disease were constantly occurring in my practice, which led we to feel the necessity of a formula for a liquid compound of iodine and opium. After having searched my library in vain for such a formula, I devised, and have since used, the one which, with your permission, I will now give to your readers.

I will here premise by saying that 1 keep constantly on hand, as a basis to the preparation $I$ am about to suggest, and also as a basis to various other preparations which I use, a solution of iodine, which is essentially one of Lugol's formula, and the merits of which are, that is an aqueous solution, and that it will keep any length of time. 'The proportions are as follows. R. lodine, $\ni$ i.; hydriodate of potash, 9 ij.; soft water, $\mathrm{f}_{3} \mathrm{i}$. Dissolve. My formula is the following. R. Of the alove, $\mathrm{f} 3 \mathrm{i}$.; sulphate of morphia, gr. i.; alcohol, $f z$ iv. ; soft water, warm, $f z$ iii. First dissolve the morphia in the water, then add the alcohol, and, lastly, 